International Journal of Social Science (IJSS)

Vol.1 No.2 August 2021, pp: 49-54

ISSN: 2798-3463 (Printed) | 2798-4079 (Online)

DOI: https://doi.org/10.53625/ijss.v1i2.136

\title{
THE RELATIONSHIP OF CLASS II ADOLESCENT GIRLS KNOWLEDGE ABOUT BREAST CANCER WITH ATTITUDES TO CONDUCT CLINICAL BREAST EXAMINATIONS (CBE) AT SMA N 8 BATAM CITY
}

\author{
By \\ Indah Mastikana ${ }^{1}$, Febri Hartini Janet Laga ${ }^{2}$, Aminah Aatinaa Adhyatma ${ }^{3}$ \\ ${ }^{1,2,3}$ Midwifery Study Program, Awal Bros Batam Health Science College \\ Email: 1indahmst2@gmail.com
}

\begin{tabular}{l}
\hline \hline Article Info \\
\hline Article history: \\
Received May 8, 2021 \\
Revised June 24, 2021 \\
Accepted July 21, 2021
\end{tabular}

Keywords:

Knowledge

Attitude

CBE Examination

\begin{abstract}
In Indonesia, the morbidity rate caused by cancer is still high. Cancer can attack all levels of society regardless of social status, age and gender. According to Mardiana (2010), it is estimated that around 60\% of cancer patients are women, especially in vital organs such as the breasts and other organs such as the uterus, ovaries and vagina. Awareness of the importance of understanding what and how breast cancer is very important for early adolescents so that adolescents can detect breast cancer early, detecting breast cancer can be done at health service centers, namely through Clinical Breast Examinations (CBE). This study aims to determine the relationship between knowledge of young women about breast cancer with attitudes to perform Clinical Breast Examinations (CBE). This research is a descriptive study with a cross sectional approach, the sample was taken by accidental sampling technique with a sample of 150 people. The results of the study most of the respondents had poor knowledge about CBE examination, from the results of the Chi-square test, the $\mathrm{p}$ value of 0.980 was greater than the $\mathrm{p}$ table, which was 0.5 , meaning that there was no relationship between the knowledge of young women and the attitude to carry out Clinical Breast Examinations (CBE). The conclusion from the results of the study is that the majority of good knowledge have attitudes in the strong category (30.6\%), have good knowledge and have moderate attitudes $(9.0 \%)$, lack knowledge and have attitudes in the strong category (6.5\%), and lack of knowledge has an attitude in the medium category (13.9\%).
\end{abstract}

This is an open access article under the CC BY-SA license.

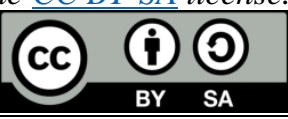

\section{Corresponding Author:}

Indah Mastikana, Febri Hartini Janet Laga, Aminah Aatinaa Adhyatma

Midwifery Study Program

Awal Bros Batam College of Health Sciences

Abulyatama Street, Belian. Batam Center. Batam City

Email: indahmst2@gmail.com

\section{INTRODUCTION}

In Indonesia, the morbidity rate caused by cancer is still high. According to 2018 Global Cancer Observatory data from the World Health Organization (WHO), the most common cancer cases in Indonesia are breast cancer, which is 58,256 cases or $16.7 \%$ of the total 348,809 cancer cases. Cervical cancer (neck of the womb) is the second most common type of cancer in Indonesia, with 32,469 cases or 9.3\% of the total cases. Cancer is still a serious health problem in Indonesia. The Ministry of Health (Kemkes) stated that the prevalence of cancer has 
increased in the last five years. According to the Basic Health Research (Riskesdas) in 2018, the prevalence of cancer in Indonesia reached 1.79 per 1000 population, up from 2013 as much as 1.4 per 1000 population. However, according to Mardiana (2010), it is estimated that around 60\% of cancer patients in Indonesia are women. Women are quite susceptible to cancer attacks, especially in vital organs such as the breast and other organs such as the uterus, ovaries and vagina.

According to data from the Riau Province Health Office in 2017, the coverage of early detection of breast cancer for women has reached the target of $20 \%$ for women aged 30-50 years, where the previous year the coverage for early detection of breast cancer was $1.1 \%$. Early detection of breast cancer is carried out using the Clinic Breast Examination (CBE) method by trained health personnel which can be carried out at the Puskesmas and its network inside and outside the building (Riau Islands Provincial Health Office, 2018). As for Batam City, based on the results of patient diagnoses at Embung Fatimah Hospital in January - December 2015, 739 people had breast cancer from 105,870 with the highest prevalence at the age of 25-50 years, both inpatients and outpatients. There is also a acknowledgment from the Batam Sei Panas Health Center that there has never been a patient who has done the Clinical Breast Examinations (CBE) as an effort to detect breast cancer early.

Awareness of the importance of understanding what and how breast cancer is very important so that women are able to detect each symptom early so that the cancer can be treated early. If the cancer is detected early, the treatment is effective and efficient so that it is not too dangerous and can even be handled completely (Diananda, 2010). To detect the presence of breast cancer can be done in an easy way and can be done yourself at home, namely with Breast Self-Examination (BSE). This action is very important because almost $85 \%$ of breast lumps are found by the sufferer themselves (Dyayadi, 2010). Likewise, according to WHO 2009, more than 50\% of women diagnosed with breast cancer have never done screening, only $20 \%$ to $30 \%$ of women do BSE (4.1\%) who do it regularly every month. However, public interest in doing BSE is still very low, this is much influenced by women's ignorance about the dangers of breast cancer, while knowledge is still influenced by education and socio-economics. CBE is a physical examination carried out by trained health personnel as part of a health examination (Yaffe MJ, 2011). In addition, there is still an assumption that breast cancer cannot be cured and is just a waste of time (Eliyani, 2011). Prevention of breast cancer in the form of health services carried out by the government includes activities that are curative, rehabilitative and palliative, by means of diagnosis, therapy, prognosis and palliative services that must be carried out by doctors and midwives. It must be implemented in an integrated manner to ensure an improvement in the patient's quality of life.

The main problem with BSE is disorganization and is rarely done correctly. So it is necessary to intervene in the form of training to improve knowledge, attitudes and practices (Erniyati, 2010). The cure will be higher if breast cancer (Ca Mammae) is found in an early stage, which is usually still small. The lack of information and efforts to publish early detection of breast cancer causes the discovery and treatment of cancer cannot be managed properly. One of the efforts to provide information about BSE to adolescent women is through health education (Melda S, 2011).

Based on this background, it can be seen that knowledge greatly influences one's actions so that good health promotion is needed about CBE examinations to the adolescent group. adolescents with attitudes to perform Clinical Breast Examinations (CBE).

\section{RESEARCH METHOD}

This research activity was carried out with quantitative research methods whose research design was analytic, namely research using a cross sectional approach, namely research was carried out on several populations that were observed at the same time (Hidayat, 2010). This research was conducted on teenage students of SMAN 8 Batam City in Bengkong Sadai with a total population of 300 students and the sample of this study used Non Random Sampling, namely sampling is not random or sampling is based on the possibility that can be calculated but solely based solely on practical aspects. The method in this study uses the Accidental Sampling technique, namely taking respondents who happen to exist or are available in a place according to the research context (Notoatmodjo, 2010). The samples obtained were 144 people.

The instrument in this study used a questionnaire to measure knowledge and attitudes in conducting CBE examinations. The data collection technique used by the researcher is using primary data obtained from the results of questionnaires by respondents and using secondary data obtained from existing data in Health Service Agencies. The data collection technique in this study started from applying for a land permit then starting to determine the number of population and samples and then the researcher determined the respondents who met the inclusion criteria and the researcher distributed the Informed Consent sheet first to the respondents and collected primary data such as filling out questionnaires, after the data was collected. The researcher carried out data processing, namely by editing, coding, data recapitulation, data entry followed by data analysis methods 
International Journal of Social Science (IJSS)

Vol.1 No.2 August 2021, pp: 49-54

ISSN: 2798-3463 (Printed) | 2798-4079 (Online)

DOI: https://doi.org/10.53625/ijss.v1i2.136

such as univariate and bivariate analysis, after analyzing the data the researchers presented in the form of exposure to the final results using tables and pie charts.

\section{RESULTS AND ANALYSIS}

3.1 RESEARCH RESULT

3.1.1 Univariate Analysis Results

a. Knowledge

Frequency Distribution of Young Women Based on Knowledge of Clinical Breast Examinations (CBE) at SMAN 8 Batam in 2018.

\begin{tabular}{ccc}
\hline Knowledge & Frequency (f) & Percentage (\%) \\
\hline Good & 57 & 39,6 \\
Less & 87 & 60,4 \\
\hline Total & $\mathbf{1 4 4}$ & $\mathbf{1 0 0}$
\end{tabular}

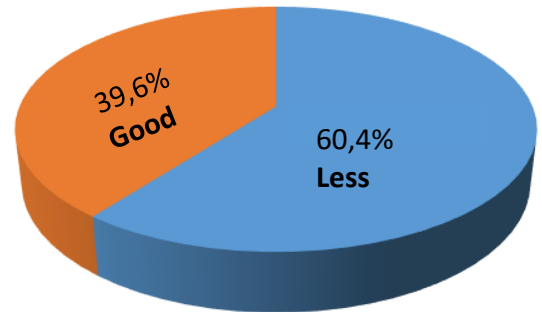

Based on the table and pie chart above, it shows that of the 144 Young Women Respondents, most of them have poor knowledge about breast cancer in the CBE examination as many as 87 respondents $(60.4 \%)$ compared to respondents who have good knowledge as many as 57 people $(39.6 \%)$.

b. Attitude

Frequency Distribution of Young Women Based on Attitudes about Clinical Breast Examinations (CBE) at SMAN 8 Batam in 2018.

\begin{tabular}{ccc}
\hline Attitude & Frequency (f) & Percentage (\%) \\
\hline Strong & 111 & 77,1 \\
Medium & 33 & 22,9 \\
\hline Total & $\mathbf{1 4 4}$ & $\mathbf{1 0 0}$
\end{tabular}

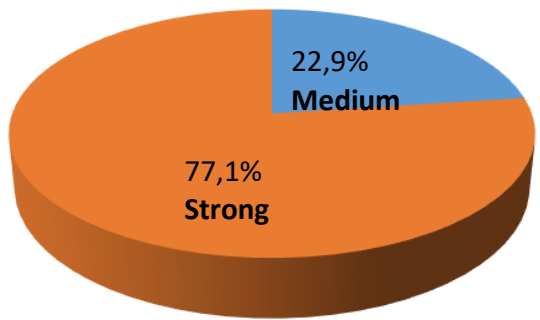

Based on the table and pie chart above, it shows that of the 144 Young Women Respondents, most of them have a strong attitude to carry out the CBE examination as many as 111 people $(77.1 \%)$, compared to a moderate attitude as many as 33 people $(22.9 \%)$.

3.1.2 Bivariate Analysis Results 
The results of the bivariate analysis aimed to determine the relationship between the knowledge of Class II Adolescent Girls with the attitude to carry out Clinical Breast Examinations (CBE) at SMAN 8 Batam.

The Relationship between Class II Adolescent Girls Knowledge About Breast Cancer With Attitudes to Conduct Clinical Breast Examinations (CBE) at SMAN 8 Batam in 2018.

\begin{tabular}{|c|c|c|c|c|c|c|c|}
\hline \multirow{3}{*}{ Knowledge } & \multicolumn{4}{|c|}{ Attitude } & \multirow{2}{*}{\multicolumn{2}{|c|}{ Total }} & \multirow{2}{*}{ P-Value } \\
\hline & \multicolumn{2}{|c|}{ Strong } & \multicolumn{2}{|c|}{ Medium } & & & \\
\hline & $\mathbf{N}$ & $\%$ & $\mathbf{N}$ & $\%$ & $\mathbf{N}$ & $\%$ & \multirow{4}{*}{$\mathbf{0 , 9 8 0}$} \\
\hline Good & 44 & 30,6 & 13 & 9,0 & 57 & \multirow{3}{*}{100} & \\
\hline Less & 67 & 6,5 & 20 & 13,9 & 87 & & \\
\hline Total & 111 & 77,1 & 33 & 22,9 & 144 & & \\
\hline
\end{tabular}

Based on the table above, it can be seen that from 144 Young Women Respondents who had less knowledge about breast cancer with a strong attitude of conducting CBE examinations, 67 people (46.5\%), compared to those who had good knowledge. Meanwhile, there are 13 young women who have good knowledge with moderate attitudes $(9.0 \%)$ compared to those who have less knowledge. Meanwhile, there are 44 young women who have good knowledge (30.6\%) and have a strong attitude compared to those who have moderate knowledge.

From the results of the Chi-square calculation, the value of Value is 0.980 . So compared to table 0.05 so value > table, $\mathrm{Ha}$ is rejected, Ho is accepted, meaning that there is no relationship between young women's knowledge about breast cancer and attitudes to conducting Clinical Breast Examinations (CBE) at SMAN 8 Batam in 2018, From the results of the Odd Ratio, it was found that respondents with good knowledge had 10 times the opportunity to carry out Clinical Breast Examinations (CBE) examinations with moderate attitudes at SMAN 8 Batam City in 2018.

\subsection{DISCUSSION}

\subsubsection{Univariate Analysis Results}

a. Knowledge of Young Women on Breast Cancer in Clinical Breast Examinations (CBE)

Based on the results of research from 144 female adolescent respondents, it is known that most of the respondents have less knowledge as many as 87 people (60.4\%) compared to young girls who have good knowledge as many as 57 people (39.6\%). This is because some respondents do not know about the principles of the Clinical Breast Examinations (CBE) itself. In addition, most of the respondents did not know the benefits of the CBE examination itself, so there was little encouragement from within to take such an action. And vice versa when someone feels that there are benefits from an activity, then the desire or urge to do it will be stronger.

Based on the results of the study, it shows that most of the respondents have less knowledge due to the lack of information held by the respondents. In addition, they do not have experience related to breast cancer which also affects the low knowledge of young women and the lack of support from their families and the environment they live in, in addition to the lack of personal experience and people around which are factors that support the knowledge of these young women. Respondents admitted that the lack of health education provided, did not have experience related to health problems about breast cancer, and lacked social support due to ignorance about breast cancer. Preferably, before conducting health education, respondents are provided with good basic knowledge and understanding about breast cancer from the school, so that when given counseling there is an encouragement in them to maintain health behaviors for a better future.

According to Notoatmodjo (2010), knowledge is a variety of symptoms encountered and obtained by humans through the observation of reason. Knowledge arises when a person uses his mind to recognize certain objects or events that have never been seen or felt before, the event in this case is the Clinical Breast Examinations (CBE) examination. According to Notoatmodjo (2010), the factors that influence a person's knowledge are education, economy, sources of information, social relations, age and experience. Thus, lack of experience, exposure to mass media, economics and social relations will have an impact on the knowledge possessed by these young women. The more experience and exposure to mass media such as television, radio, internet, magazines, health books or health posters that are owned can increase the knowledge of young women about an object such as breast cancer with CBE examination. 
International Journal of Social Science (IJSS)

Vol.1 No.2 August 2021, pp: 49-54

ISSN: 2798-3463 (Printed) | 2798-4079 (Online)

DOI: https://doi.org/10.53625/ijss.v1i2.136

b. Attitude to Performing Clinical Breast Examinations (CBE)

Based on the results of the study, it was found that some respondents had a moderate attitude to carry out the CBE examination, as many as 33 people (22.9\%). A strong factor that influences the formation of this attitude is the emotional factor in oneself that has a positive preconception of the desire to be healthy. Attitudes are carried out in the moderate category if humans have positive knowledge, have good judgment, but have low reactive readiness to a situation. Many experts say that behavior does not necessarily indicate an attitude (Notoatmodjo, 2010).

Of the three attitude factors that influence attitudes, namely knowledge which has the highest number. This is because Young Women have limited knowledge but have good rective readiness. The results of this study are in line with the statement of Wawan, A and Dewi (2010) that it does not mean that someone with low knowledge is absolutely low educated, the more positive aspects and objects that are known, the more positive attitudes towards certain objects will arise. The limitations of knowledge, technology and the social environment are able to limit a person's attitude towards something, this is in accordance with the assumption that people will tend to avoid things that cause fear and trouble or contain heavy risks and prefer to do something that brings pleasure to them.

Attitude exists or occurs because of a person's need for knowledge. To achieve the goal of attitude as a driving force, the fuel is knowledge. Respondents feel they need knowledge, so they are able to be more confident about their reactive readiness to the process of acting in order to have a positive attitude as evidenced by the high attitude of respondents due to the need for knowledge. This is not in line with the results of research conducted by Tri Ambarwati et al (2012) on young women at SMAN 1 Klaten who said that one of the factors that influenced their attitude to do so was from their own friends. This is in accordance with the theory put forward by Priyanto (2009), which states that there are two kinds of support, namely natural support and artificial support. Natural support is support obtained from the closest people, including family and close friends. While the source of artificial support is a source of support that is intentionally formed to provide assistance such as support groups, counselors and health workers.

Young women do not do CBE for various reasons, such as fear of a positive test result, feeling that they are not at risk for breast cancer, not knowing about CBE, and feeling afraid. If this is not followed up immediately, it is feared that there will be further growth in breast cancer which is getting higher. The cause of the increasing prevalence of breast cancer is due to lack of awareness to utilize CBE services and lack of understanding about breast cancer and CBE. Notoatmodjo (2010), states that in order for a person to act to treat or prevent his illness, he must feel that he is susceptible to the disease. Preventive behavior against breast cancer will arise if a person feels that he is at risk for developing the disease. Vulnerability is a subjective condition so that the acceptance of individuals, especially people at high risk of susceptibility to breast cancer infection can vary.

\subsubsection{Bivariate Analysis Results}

a. Relationship between knowledge of young women and attitudes to conducting clinical breast examinations (CBE)

Based on the results of the study, it shows that respondents who have less knowledge have attitudes in the strong category, while respondents who have good knowledge have attitudes in the medium category. The results of the correlation test showed that there was no significant relationship between the knowledge of young women and the attitude to carry out the Clinical Breast Examinations (CBE) at SMAN 8 Batam City. Young women who have less knowledge, while young women who have less knowledge with strong attitudes are $67(46.5 \%)$ compared to respondents who have good knowledge and have moderate attitudes as many as $13(9.0 \%)$.

Most of the young women knew little about the CBE examination to detect breast cancer in the body, but they admitted that they had never had the examination because they had no risk factors. Respondents who have good knowledge about the CBE examination also have a strong attitude in carrying out the examination. Respondents' knowledge will influence their attitude to carry out an examination of their will, without any pressure from various parties. This is because there are other factors that influence a person's attitude, namely personal experience, culture, closest people who are considered important, mass/electronic media, educational institutions, emotional factors in oneself.

Human behavior is the result of all kinds of experiences and interactions between humans and the environment which are manifested in the form of knowledge, attitudes and actions. Behavior is 
formed through a process and takes place in the interaction of humans and the environment. The factors that influence the formation of behavior are divided into two, namely internal and external factors. Internal factors include knowledge, intelligence, emotions, innovation and so on which function to process external stimuli. External factors include the surrounding environment, both physical and nonphysical, such as climate, socio-economics, culture and so on.

The formation of a new behavior, especially in adults, starts from the subject knowing in advance of the stimulus in the form of material or knowledge, because it creates new knowledge on the subject, it then causes an inner response in the form of the subject's attitude towards the known object. In the end, the stimulus is fully realized and will cause a further response in the form of action or behavior. This research is supported by the statement of Notoatmodjo (2010), which states that in order for a person to act to treat or prevent his disease, he must feel that he is susceptible to the disease, so that young women are motivated to perform CBE examinations even though they have less knowledge about breast cancer.

Based on conclusions from several sources, it was found that there was no relationship between knowledge and attitudes to do CBE, this was because it was not only pure knowledge that influenced the attitudes of young women, but there were other factors that led to high attitudes of young women such as experience and environmental encouragement around.

\section{CONCLUSION}

Based on the results of research and data processing that has been carried out by researchers regarding the relationship between knowledge of grade II adolescent girls about breast cancer with attitudes to conducting Clinical Breast Examinations (CBE) at SMAN 8 Batam City in 2018 with a total of 144 respondents, it can be concluded that:

The results showed that of the 144 second grade adolescent girls, at SMAN 8 Batam City, most of them had good knowledge of 57 (39.6\%) and 87 (60.4\%) who had less knowledge about Clinical Breast Examinations (CBE).

a. The results showed that out of 144 young women at SMAN 8 Batam City, $111(77.1 \%)$ had strong attitudes and $33(22.9 \%)$ had moderate attitudes in conducting the Clinical Breast Examinations (CBE).

b. There is no significant relationship between the knowledge of young women with attitudes to perform Clinical Breast Examinations (CBE) at SMAN 8 Batam City.

\section{ACKNOWLEDGEMENTS}

The team of authors would like to thank all those who have helped the smooth implementation of this research at SMAN 8 Batam City and the entire academic community of STIKes Awal Bros Batam and Bangun Bangsa Foundation.

\section{REFERENCES}

[1] Agus, Riyanto and Budiman. 2013. Capita Selecta. Knowledge and Attitude Questionnaire in Health Research. Jakarta: Salemba Medika

[2] Alimul, Hidayat. 2010. Midwifery Research Methods and Data Analysis Techniques. Jakarta: Rineka Cipta.

[3] Riau Provincial Health Office, 2018. Riau Province Health Profile 2017. Downloaded via website: https://dinkes.riau.go.id/sites/default/files/202012/Profil\%20Kesehatan\%20Provinsi\%20Riau\%20Tahun\%202017.pdf.

[4] Erawantini, F., \& Nurmawati, I. (2016). BSE Training (Breast Self-Examination) for Students of SMKN 5 Jember as an Effort to Prevent Breast Cancer. Proceedings.

[5] Globocan, 2012. Estimated Cancer Incidence, Mortality And Prevalence Worldwide In 2012. http://globocan.iarc.fr/Pages/fact_sheets_cancer.aspx [accessed March 09, 2016.

[6] Ministry of Health. National Program Guide for Prevention and Early Detection of Cervical Cancer and Breast Cancer. Jakarta: Directorate General of Disease Control and Environmental Health, Directorate of NonCommunicable Disease Control, Ministry of Health of the Republic of Indonesia; 2015.

[7] KPKN. National Guide to Cancer Management "Breast Cancer". Jakarta: Indonesian Ministry of Health; 2015.

[8] Notoatmodjo, Soekidjo. 2010. Health Promotion and Health Behavior. Jakarta: Creative creations.

[9] Sudarmi, S., \& Nurchairina, N. (2017). Implementation of Early Detection of Breast Cancer and Cervical Cancer Using the CBE and IVA Methods in South Lampung Regency. Journal of Health, 8(2), 225-234. 